\title{
Research on Operation Optimization Strategy of Integrated Energy System Considering Ground Source Heat Pump
}

\author{
Linfeng Wang ${ }^{1}$, Kai Zhang ${ }^{1}$, Nan Xu ${ }^{1}$, JingyanWang ${ }^{2}$, Danyang Zhang ${ }^{2}$, Shuo Wang ${ }^{2}$, Yongli Wang ${ }^{2}$ \\ ${ }^{1}$ State Grid Hebei Economic Research Institute, Shijiazhuang 050000, China \\ ${ }^{2}$ Departments of Economics and Management, North China Electric Power University, Beijing 102200, China
}

\begin{abstract}
With the depletion of fossil energy and the popularity of renewable energy, a comprehensive energy system with the goal of improving system energy efficiency and consuming renewable energy is booming. Based on the combined heat, power, and heat generation, this paper builds a comprehensive energy system operation optimization model in conjunction with ground source heat pumps. It aims to find the optimal operation strategy based on the actual situation of the park's load, equipment capacity, and energy prices. Using the linear programming method, a mathematical model with the best economic efficiency of the integrated energy system is established, the optimal operation strategy for a typical day is analyzed, and the annual operation is simulated. Finally, it compares with conventional energy supply methods and analyzes the contribution to the consumption of renewable energy.
\end{abstract}

\section{Introduction}

Natural gas cold, heat and power triple supply system follows the "temperature pair. The principle of using the mouth and energy cascades. The utilization efficiency of the source is maximized [1]. Therefore, the triple supply system has developed very well in recent years because of its high energy efficiency and environmental friendliness.

With the increasing installed capacity of renewable energy power generation Plus, its power generation ratio has also increased year by year, wind power generation by the end of 2017 has reached $188.39 \mathrm{GW}$. However, renewable energy generation is intermittent and random. Characteristics [2,3], installed with $200 \mathrm{~kW}$ wind power ${ }^{1}$. As an example of equipment, it can be seen that wind power fluctuates at night and during the day. Sexually large. Wind power generation in the first half of 2018 was 191.7 billion $\mathrm{kWh}$, abandoned wind power of 18.2 billion $\mathrm{kWh}$ [4], abandoned wind peak. It is necessary to concentrate on the moment when the wind power output is large at night. Abandoned wind power. In the middle of the night, electricity consumption is about $60 \%$ [5].

In order to meet the heat load demand of the building, the traditional triple supply system operates in the "heat-set" mode, and the excess electricity brought about to ensure heating will not be absorbed. If the system is operated in the "heat setting" mode, the heating will not be satisfied due to insufficient heat [6]. Therefore, the thermos electrics are coupled to each other, resulting in a system that cannot be flexibly adjusted. In view of the above problems, this paper constructs a three-in-one integrated energy system coupled with ground source heat pump. Through the optimal adjustment of the system, thermal electrolysis is realized, which provides enough space for renewable energy to access the Internet.

\section{Introduction to integrated energy system}

The integrated energy system studied in this paper is composed of gas internal combustion engine, flue gas driven absorption type hot and cold water unit, ground source heat pump, electric refrigerator, regenerator, gas boiler and so on. The flow chart of the system is shown in Figure 1.

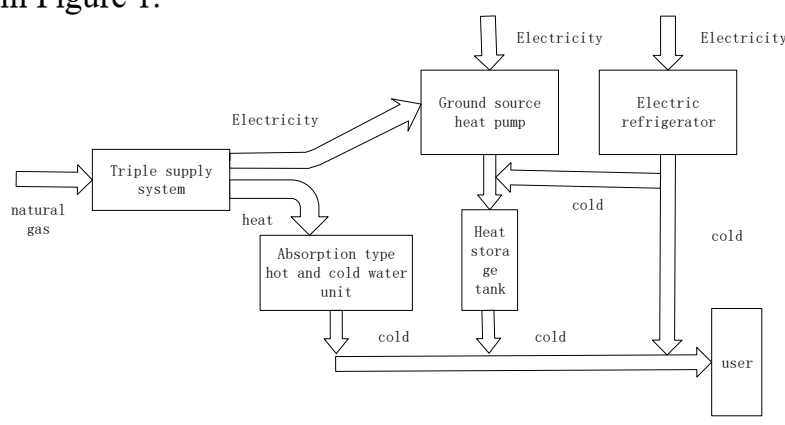

Fig. 1. Integrated Energy System flow chart

In the winter, natural gas enters the generator set to generate electricity. The generated flue gas $\left(458^{\circ} \mathrm{C}\right)$ and cylinder water $\left(90^{\circ} \mathrm{C} / 70^{\circ} \mathrm{C}\right)$ enter the absorption hot and cold water unit to obtain hot water $\left(60^{\circ} \mathrm{C} / 50^{\circ} \mathrm{C}\right)$. The electricity of the generator is used to drive the ground 
source heat pump to heat, the insufficient electricity is purchased from the grid, and the insufficient heat is supplemented by the gas boiler. In summer, natural gas enters the generator set, and the flue gas and cylinder water after power generation enters the absorption chiller to drive the absorption refrigeration mechanism to take cold water $\left(6^{\circ} \mathrm{C} / 12^{\circ} \mathrm{C}\right)$. The electricity of the generator is used to drive the ground source heat pump. And electric refrigerator cooling, to meet the building's cooling load demand, not enough electricity purchased from the grid. How to adjust and control the coordinated operation between the various devices in the triple-supply system to minimize operating costs and maximize energy utilization efficiency has become the key to research. In the following, based on the performance characteristics of the various components of the integrated energy system, the mathematical model of each component is established to find the optimal operation strategy.

\section{Integrated energy system optimization model}

All the equipment in the integrated energy system is not isolated and should be coordinated with each other, so that the whole system can be in optimal operation [7]. The mathematical model will be built based on the role and characteristics of the various components in the system. The optimization analysis was carried out in one hour as the operating cycle and in steps of one hour $(\mathrm{i}=$ $0,1,2, \ldots 22,23)$.

\subsection{Objective function}

According to the above analysis, the objective function is established, the operating cost of heating within one day is minimal:

$$
\begin{gathered}
f(x)=\sum_{i=0}^{23}\left(P_{\text {gas }} G_{\text {ige }}+P_{\text {gas }} G_{\text {iboiler }}+P_{e i} E_{\text {ibuy }}\right) \\
F=\sum_{j=1}^{365} f(x) \\
w=\frac{W}{N} \\
Z=F+w \\
z=\frac{Z}{Q}
\end{gathered}
$$

In the above formula, $f(x)$ stands for objective function. $F$ is annual operating costs. $Z$ is equipment depreciation expense. $z$ stands for energy supply cost. $P_{g a s}$ is the price of natural gas, yuan $/ \mathrm{Nm}^{3} . P_{e i}$ is time-sharing electricity price, yuan $/ \mathrm{kWh} . W$ is the total investment of the project, $N$ is the depreciation period. $Q$ is the energy for the whole year, GJ.

\subsection{System energy balance}

The building's thermal and thermal loads are all provided by the system, so the building's thermal and thermal loads are guaranteed at each moment. For the power load, the triple supply system is a type that does not connect to the Internet, that is, the triple-connected unit can not generate electricity for power generation, the power generation meets the self-use of electricity in the energy station, and the insufficient power is purchased from the power grid. According to the output of the equipment and the load demand of the building. The following constraints are as follows:

$$
\begin{aligned}
& Q_{\text {iload }}^{h}=Q_{i c c h p}^{h}+Q_{i s e h p}^{h}+Q_{i \tan K}^{h}+Q_{i b o i l e r}^{h} \\
& E_{i}+E_{i b u y}-E_{i s e h p}^{h}=0 \\
& Q_{i l o a d}^{c}=Q_{i c c h p}^{c}+Q_{i s e h p}^{c}+Q_{i \tan K}^{c}+Q_{i b o i l e r}^{c} \\
& E_{i}+E_{i b u y}-E_{i s e h p}^{c}-E_{i e c}^{c}=0
\end{aligned}
$$

In the formula, $Q_{\text {iload }}^{c}, Q_{\text {iload }}^{h}$ - the cold load and heat load of the building at the moment, $\mathrm{kW} ; E_{i b u y}$ - the power purchased at the grid, $\mathrm{kW}$.

\section{Case analysis}

\subsection{Basic information of the project}

The integrated energy system bears the cooling and heating load of the building area. The cooling load of the building is $40.56 \mathrm{MW}$ in summer and hot in winter. The load is $18.84 \mathrm{MW}$ according to the construction load, the specific equipment capacity and quantity allocation are shown in Table 1.

Table 1. Equipment Capacity Configuration

\begin{tabular}{c|c|c}
\hline Device name & Capacity /kW & $\begin{array}{c}\text { Number } \\
\text { of tables }\end{array}$ \\
\hline Alternator & 800 & 3 \\
\hline $\begin{array}{c}\text { Flue Gas Waste Heat } \\
\text { Thermal Water Unit }\end{array}$ & $\begin{array}{c}876 \text { (heating) } \\
\text { (refrigeration) }\end{array}$ & 2 \\
\hline $\begin{array}{c}\text { Ground source heat } \\
\text { pump }\end{array}$ & $\begin{array}{c}\text { 1443(heating) } \\
\text { (refrigeration) }\end{array}$ & 5 \\
\hline Gas fired boiler & 4200 & 2 \\
\hline Electric refrigerator & 6680 & 3 \\
\hline Regenerative tank & $16800(\mathrm{~m})^{3}$ & 1 \\
\hline
\end{tabular}

The total investment of this project is 202 million yuan. The values of energy prices and key parameters are shown in tables 2 and3.

Table 2. Values of important parameters

\begin{tabular}{c|c}
\hline key parameter & Value \\
\hline ETAE & $40 \%$ \\
\hline Cophsehp & 4.26 \\
\hline Copcsehp & 5.97 \\
\hline Copcec & 4.98 \\
\hline
\end{tabular}




\begin{tabular}{c|c} 
ETA boiler & $95 \%$ \\
\hline
\end{tabular}

Table 3. Hourly Price Distribution

\begin{tabular}{c|c}
\hline TOU price & $\begin{array}{l}\text { Unit price } \\
\text { (yuan/kWh) }\end{array}$ \\
\hline 23:00-7:00 & 0.4262 \\
\hline 7:00-10:00/15:00-18:00/21:00-22:00 & 0.9138 \\
\hline $10: 00-15: 00 / 18: 00-20: 00$ & 1.2856 \\
\hline
\end{tabular}

The price of natural gas is 2.39 yuan/Nm.3According to the equipment parameters, building load and energy price, according to the constraints mentioned above, the operation mode of the system is simulated and analyzed by the built-in optimization toolbox and programming language of MATLAB software.[10]

\subsection{Result analysis}

\subsubsection{Seasonally typical days}

The typical daily load is shown in Fig. 2. After the above simulation and optimization, the specific operation strategy is shown in Fig. 3 and Fig. 5.

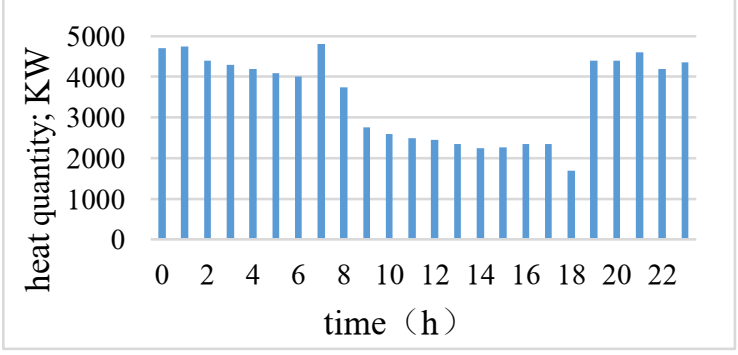

Fig. 2. Composition of Building Heat Load on Typical Days

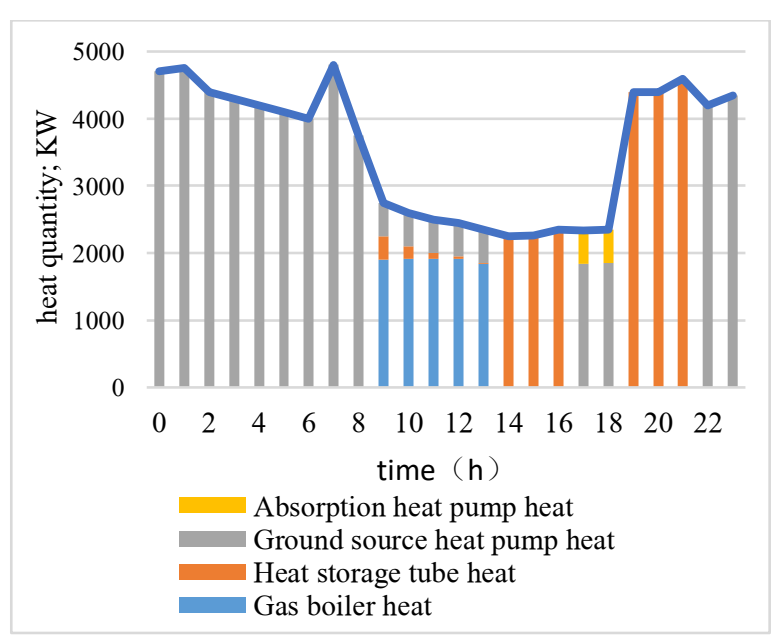

Fig. 3. Typical Daily Energy Supply

Fig. 3 shows the output of each equipment in the optimized system. During the low power load period (23:00-6:00), the ground source heat pump (GSHP) driven by purchasing electricity from the power grid operates at full load. On the premise of meeting the building heat load, the excess heat of GSHP is stored in the storage tank. During peak load period (9:00-14:00).
From 18:00 to 20:00, the internal combustion engine generates electricity, drives the ground source heat pump to make heat, and flue gas drives the absorption chiller and water heater to make heat. At this time, the heat storage tank releases the stored heat, and the absorption chiller jointly bears the heat load of the building. Figure 3 shows the detailed storage state of the regenerator.

\subsubsection{Annual operation energy consumption analysis}

Heating operation as shown in Table 4.Using the integrated energy system and operating under the optimized strategy, the operating cost of the whole heating season is 3665,800 yuan, the equipment is depreciated according to its 30-year service life, and the heating cost is as follows:62.15 Yuan/GJ is lower than the heating cost of natural gas boilers. Under this operation strategy, 1.64 million $\mathrm{kWh}$ is purchased to provide 1.64 million $\mathrm{kWh}$ of Internet space for renewable energy generation.

Table 4. Heating Season Operation

\begin{tabular}{c|c|c}
\hline \multirow{2}{*}{$\begin{array}{c}\text { Natural gas consumption } \\
(\mathbf{1 0 0 0 0} \mathbf{~ N m}) \mathbf{3}\end{array}$} & $\begin{array}{c}\text { Air intake of } \\
\text { triple supply }\end{array}$ & 81.56 \\
\cline { 2 - 3 } & $\begin{array}{c}\text { Gas Boiler Intake } \\
\text { Volume }\end{array}$ & 40.5 \\
\hline \multirow{4}{*}{$\begin{array}{c}\text { Electricity statistics (10000 } \\
\text { kWh) }\end{array}$} & $\begin{array}{c}\text { Internal } \\
\text { combustion } \\
\text { engine power } \\
\text { generation }\end{array}$ & 300.78 \\
\cline { 2 - 3 } & $\begin{array}{c}\text { Power grid } \\
\text { purchase }\end{array}$ & 164.5 \\
\cline { 2 - 3 } $\begin{array}{c}\text { Power } \\
\text { Consumption of } \\
\text { Ground Source } \\
\text { Heat Pump }\end{array}$ & 486.7 \\
\hline \multirow{2}{*}{$\begin{array}{c}\text { Heating statistics } \\
(\mathbf{1 0 0 0 0} \text { GJ) }\end{array}$} & $\begin{array}{c}\text { Ground Source } \\
\text { Heat Pump } \\
\text { Heating }\end{array}$ & 6.5 \\
\cline { 2 - 3 } & $\begin{array}{c}\text { Gas-fired Boiler } \\
\text { Heating }\end{array}$ & 1.5 \\
\hline $\begin{array}{c}\text { Annual operating cost (10,000 } \\
\text { yuan) }\end{array}$ & 366.58 \\
\hline
\end{tabular}

\section{Conclusion}

In this paper, an integrated energy system coupled with ground source heat pump (GSHP) is proposed, and its operation is optimized. Under the optimized operation strategy, the integrated energy system embodies the unique dual advantages of economy and energy saving.

Under the premise of satisfying the energy supply, the optimized integrated energy system not only provides enough space for renewable energy to access the Internet, but also saves a lot of operating costs. The distributed cogeneration system with integrated energy utilization is an efficient and economical distributed energy system. It has good development potential in the consumption of renewable energy and thermal 
decoupling of energy system.

\section{Acknowledgement}

State grid technology project (SGHEJY00JJJS1900017)

\section{References}

1. Fu Lin, Li Hui. Technology and Application of Natural Gas Cogeneration of Heat, Power and Cooling. Beijing: China Construction Industry Press, 2008

2. Zhang Guangjun, Feng Yuan. Research on wind farm output characteristics based on measured data Research. Wind Energy, 2016 (03): 82-84

3. Tianru. Research and Application of Wind Power Output Characteristics. [Master\&apos;s Degree Thesis]. North China Electric Power University. Beijing: 2013

4. Wang Xiaotao. Expanding the scale of renewable energy power generation, expanding wind abandonment and power limitation, and continuing mitigation [N]. China Economic Report, 2018-08-07 (005)

5. Ge Weichun. Analytical Method of Hourly Abandoned Wind Power in Power Grid [J] Journal of Solar Energy: 1-6

6. Zhao Xiling, Zhang Xingmei and Fulin. Energy-storage cogeneration device and its operation method suitable for active distribution network. CN104697238A,2015

7. Jiang, Y., et al., Coordinated operation of gas electricity integrated distribution system with multiCCHP and distributed renewable energy sources. Applied Energy, 2018, 211:237-248

8. Liu Wenjie. Applied Research of Hot Water Regenerative Tank in Cogeneration Heating System. Harbin University of Technology, 2016

9. Mahan. Operational strategy and performance analysis of combined cooling, heating and power supply system with buffered water storage. Building thermal energy, ventilation and air conditioning, 2018 (03)

10. Zhangwu. MATLAB optimization toolbox and its application [J]. Agricultural network information, 2008 (08): 138-139+142 